\title{
Investigation Flow Depth and Flow Speed Changes in the Karun River
}

\author{
Mehrab Yusefi Hagivar1 ${ }^{1}$, Mehdi Behdarvandi Askar ${ }^{1 *}$, Shariat Moalemi ${ }^{2}$ \\ ${ }^{1}$ Department of Offshore Structures, Faculty of Marine Engineering, Khorramshahr University of Marine Science and Technology, \\ Khorramshahr, Iran \\ ${ }^{2}$ Hydraulic Structures, Bureau of Natural Resources, Khuzestan, Iran \\ Email: *sazehenteghal@yaahoo.com
}

How to cite this paper: Hagivar, M.Y., Askar, M.B. and Moalemi, S. (2017) Investigation Flow Depth and Flow Speed Changes in the Karun River. Open Journal of Marine Science, 7, 289-299.

https://doi.org/10.4236/ojms.2017.72021

Received: February 4, 2017

Accepted: April 25, 2017

Published: April 28, 2017

Copyright $\odot 2017$ by authors and Scientific Research Publishing Inc. This work is licensed under the Creative Commons Attribution International License (CC BY 4.0).

http://creativecommons.org/licenses/by/4.0/

\begin{abstract}
In the present study, the Karun River in Khuzestan province in Iran is that is somehow considered the river with the most water in the country was examined. To examine the depth and speed of the flow, which undoubtedly have the greatest impact on the environment and ecosystem of the river, twodimensional simulation by CCHE2D model was used. In this study, it was observed that, firstly, the changes of depth and velocity along the river have good coordination and the highest changes were observed in the meander and arches. Moreover, due to using two-dimensional model, there is the possibility of examining changes of parameters in the longitudinal and transverse direction that shows the two-dimensional model is an efficient and powerful model in studying river flows.
\end{abstract}

\section{Keywords}

Depth Changes, Speed Changes, the Karun River, CCHE2D

\section{Introduction}

Karun River is the longest river of Iran with a length of $950 \mathrm{~km}$ originating from the Zagros Mountains and after many twists and turns in Khuzestan Plain, it pours into Pars Sea. Karun has been the formation of the earliest human civilizations. Karun has always been of great importance because of its long history in shaping and prosperity of human and indigenous culture of Khuzestan. Today, the water of this old river is used not only to provide drinking water of people of Khuzestan, agriculture needs, and power generation in the upstream, but it has a lot of potential for recreation and tourism. One of the tools to study flow in Karun River Basin is numerical models. For this purpose, one-dimensional and 
two-dimensional numerical models have been used on a limited basis. Given that the Karun River is among the wide rivers, the use of two-dimensional models and numerical simulations to study compatibility are more compatible with real-world situations. In non-viable models, it is assumed that the flow characteristics change over time. Moreover, in this paper, we assume that roughness distribution is uniform in the entire computational domain. The wind effect is ignored in the calculation. Karun riverbed is generally formed of fine-sand sediments with silt, and in terms of being meander, coastal walls are erosive. In the main part of the Karun River, the soil of the walls is fine-grained texture and prone for agricultural activities. Magrebi (2011), models MIKE21 FM and CCHE2D are compared in simulation the flow pattern in River Bend (Karun). In this study, the pattern of turbulent flow in a range of Karun River has two 180 degree sharp bend in the form of two-dimensional depth-averaged in depth was modeled in unsteady by the mode above. Output Results from the models showed that both models are qualitative models correctly simulating the flow pattern in the study area. Nevertheless, there were differences in the results of the modeling by the above-mentioned software that are due to the quality of solving equations and different abilities of the two [1]. Hayati et al. (2014) examined the effect of various flood discharges on the changes of the Kor River, located between Abbas Abad Bridge and Deroduzan Dam using CCHE2D model [2]. Compound section is referred to a section the surface of which is made of several sub-sections with different flow characteristics [3]. The difference in the hydraulic and geometry characteristics causes a complexity in flow hydraulic and creates an interaction between the main channel and floodplains, resulting in an apparent shear stress and a transverse momentum transfer [4]. This research investigates the change of the velocity on seawall crown by considering the obstacles in different layouts and slopes [5]. The intended slopes for seawalls were $22,27,32,39$ degrees, respectively and the roughness heights on wall surface were $15 \mathrm{~cm}, 20 \mathrm{~cm}$ and $30 \mathrm{~cm}$. Moreover, four types of roughness layouts on the wall surface were investigated [6]. Flow-3D software was used for this purpose and for modeling [7]. The humans' need to use the oceans for exploration and extraction of oil has led to the development of engineering science in the field of offshore structures [8]. The difference in the hydraulic and geometry characteristics causes a complexity in flow hydraulic and creates an interaction between the main channel and flood plains, resulting in an apparent shear stress and a transverse momentum transfer [9]. Today, due to increasing development in the use of marine resources as well as the growth of the maritime transportation industry, so much effort has been made to develop safe and calm environment for mooring buoys [10].

\section{Materials and Methods}

Karun river basin in terms of hydrology of Iran in general is of the Persian Gulf and Oman Sea basin. Karun is the river with most water in Iran and after Kark- 
heh with $890 \mathrm{~km}$ in length is the longest river. Karun River has four main branches called Khersan, AbVanak, AbKiar, and Bazoft. Model of flow simulation module CCHE2D is an average depth two-dimensional developed for Steady and Unsteady flows Figure 1. Modules flow is planned based on averaged Navier-Stokes equations in depth. Moreover, three options of turbulence closure are available to calculate Eddy Viscosity. Solving the equations set governing implicitly is done by volume control and effective element methods. The turbulence in this software is stimulated by five models and the model used in this research was Re-Normalisation Group (RNG) [11] [12]. The ruling parameters in the design of coastal structures include hydraulic, geotechnical, and structural parameters [13]. The authors have conducted flume experiments to simulate sediment transport of channel flows with tall rigid stems. These flows were examined for various stem densities, channel slopes and sediment sizes with uniformly-distributed unsubmerged cylindrical rigid stems forming a regular square staggering pattern in plan [14] [15].

\section{Navier-Stokes Equation}

Navier-Stokes equation for turbulent average depth two-dimensional flows is as follows:

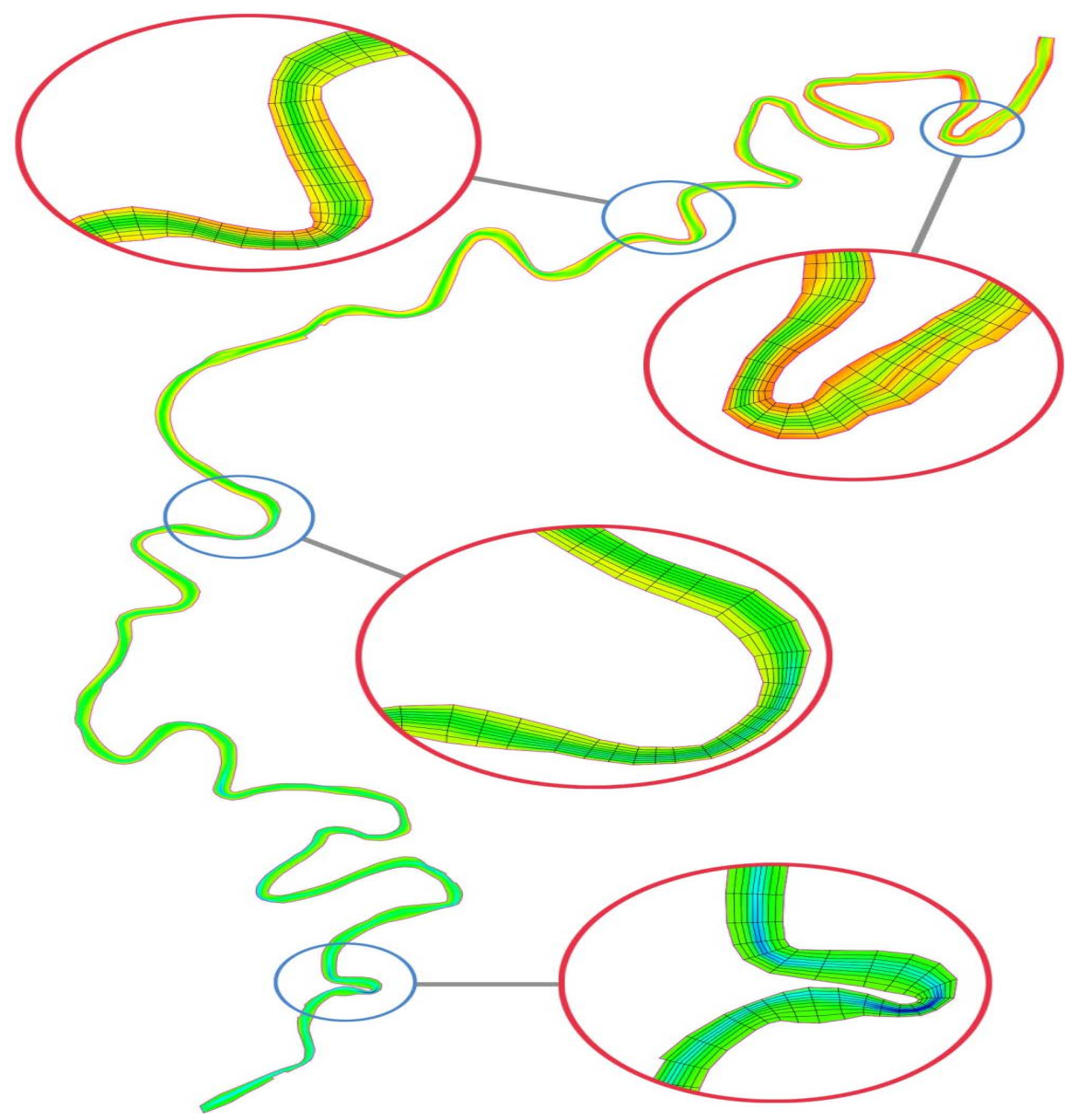

Figure 1. View of the mesh made in the model CCHE2D. 


$$
\begin{aligned}
& \frac{\partial u}{\partial t}+u \frac{\partial u}{\partial x}+v \frac{\partial u}{\partial y}=-g \frac{\partial Z}{\partial x}+\frac{1}{h}\left[\frac{\partial\left(h \tau_{x x}\right)}{\partial x}+\frac{\partial\left(h \tau_{x y}\right)}{\partial y}\right]-\frac{\tau_{b x}}{\rho h}+f_{C o r} v \\
& \frac{\partial v}{\partial t}+u \frac{\partial v}{\partial x}+v \frac{\partial v}{\partial y}=-g \frac{\partial Z}{\partial y}+\frac{1}{h}\left[\frac{\partial\left(h \tau_{y x}\right)}{\partial x}+\frac{\partial\left(h \tau_{y y}\right)}{\partial y}\right]-\frac{\tau_{b y}}{\rho h}-f_{C o r} u
\end{aligned}
$$

$u$ and $v$ are the average depth of the components in the $x$ and $y$ of local coordinates;

g. gravitational acceleration;

$Z$ : elevation of the water surface;

$\rho$ : water Density;

$h$ : Local water depth;

$\tau_{x x}, \tau_{x y}, \tau_{y x}$ and $\tau_{y y}$ Reynolds stresses of mean depth;

$\tau_{b x}$ and $\tau_{b y}$ by: shear stresses on the surface of the substrate;

$f_{\text {Cor }}$ : Coriolis parameter.

\section{Calibrating Flow Model CCHE2D}

First, to determine the number of appropriate points of computational grid, flow model was calibrated relative to it and then the calibration of the model for other computational parameters was developed. To calibrate flow models, there are two distinct varieties of parameters available. One is turbulence model that as mentioned earlier in section 3.4 includes: 1) Parabolic models mean depth 2) length complex model of mean depth and 3) two-dimensional k-emodel, and the second substrate roughness using a roughness of the bed defined by $n$ Manning roughness coefficient. Considering that, the aforementioned models aimed at vortices and rotating turbulent flow processes simulating and the flow around hydraulic structures and the impact of such flows on erosion and scour around these structures and since the range intended to do this research has been extensive, during the calibration process, it was observed that by changing turbulence model, there has been no change in the output of models. So, in calibration, the effect of this parameter was ignored due to being intangible. After the calibration of two-dimensional flow model, it is the turn for the final implementation model. At this point, the model was run for a flood for 8 days that occurred in 2015.

\section{Results}

By comparing the field view of depth and speed of the flow, it is understood that the magnitude of flow velocity is inversely related to the approximate of depth (Figure 2). According to cohesion relationship, for a given flow if the cross-flow is reduced or increased by reducing/increasing the depth or width of the cross, the speed reduces or increases in a way that flow remains the same (Figure 3). If you compare the two forms is high. As is clear in comparing the two shapes above, in places where the depth or width of the cross-flow increases, speed reduces and in places where the depth or width of the flow is reduced, speed increases. The model accuracy in calculating the depth and flow rate is desirable. In Figure 4, 


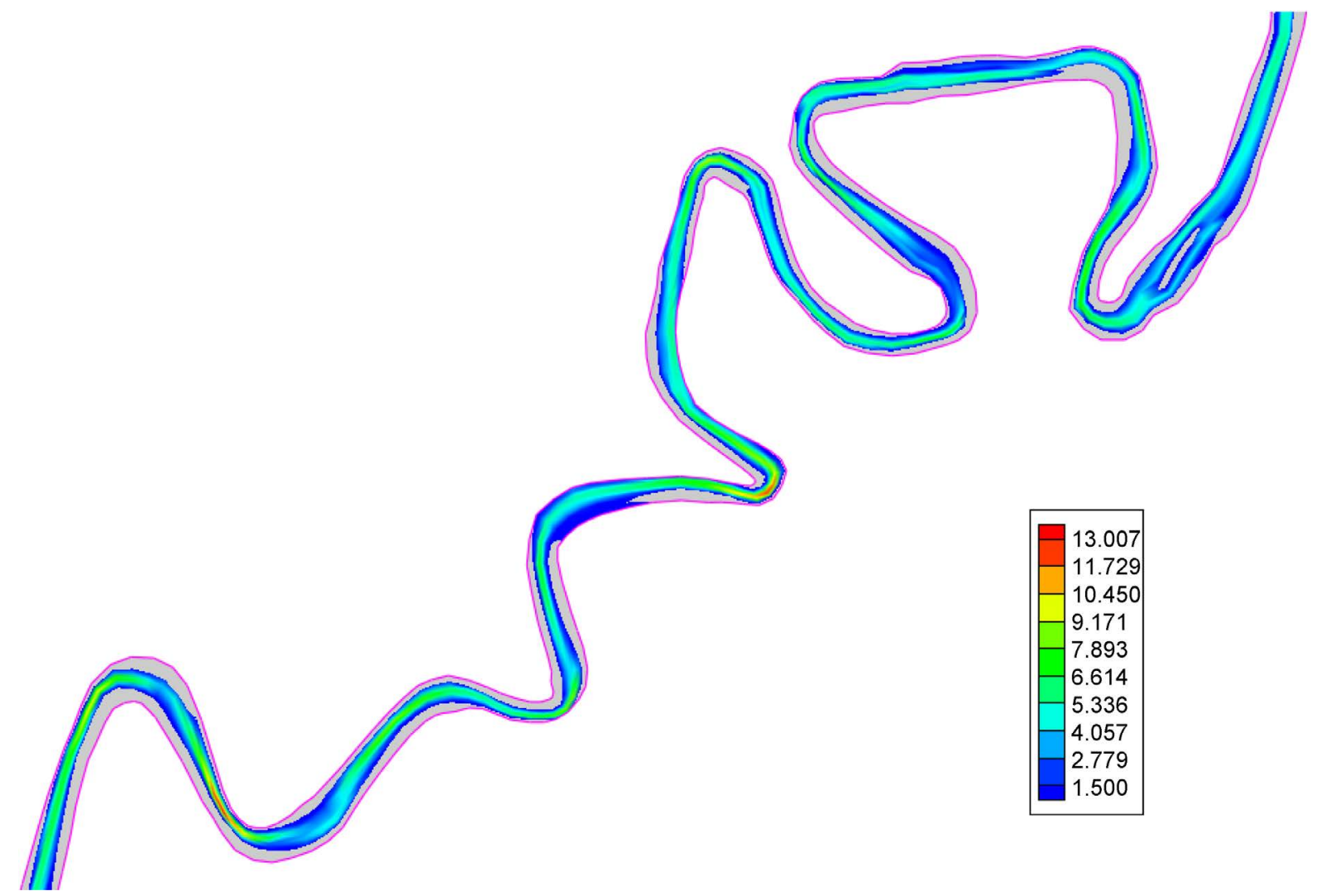

Figure 2. View of the water depth in this research field.

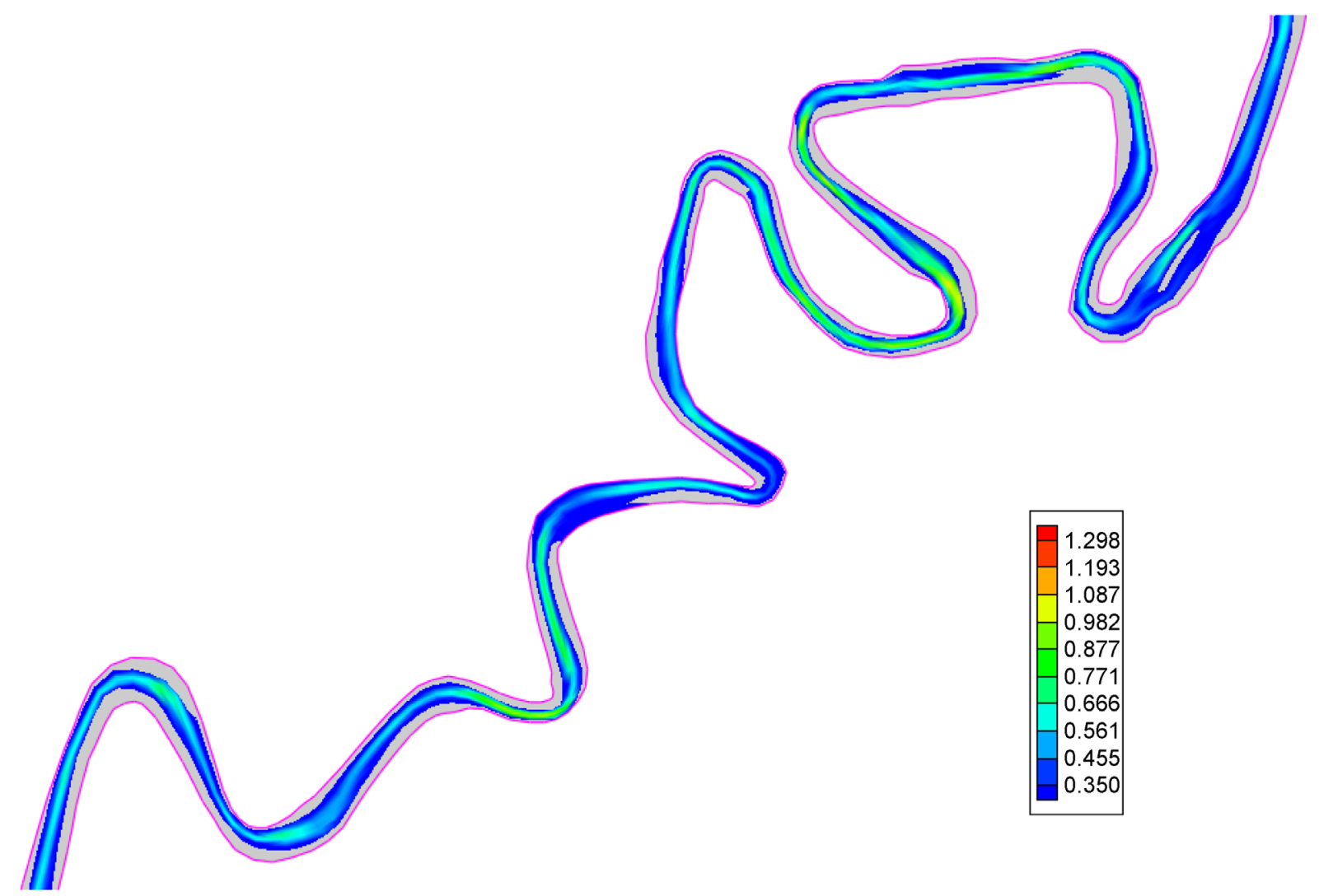

Figure 3. View of water velocity field this research. 
11 points of the path of the intended range shown are selected and for two 96 hours (peak of inflow hydrograph) and 192 hours (end of the hydrograph in eighth day) and the speed parameter against the distance has been plotted. Moreover, in Figure 5, cross sections have been examined.

In all Figures 6-15 that is in all sections and other cross sections in this study,

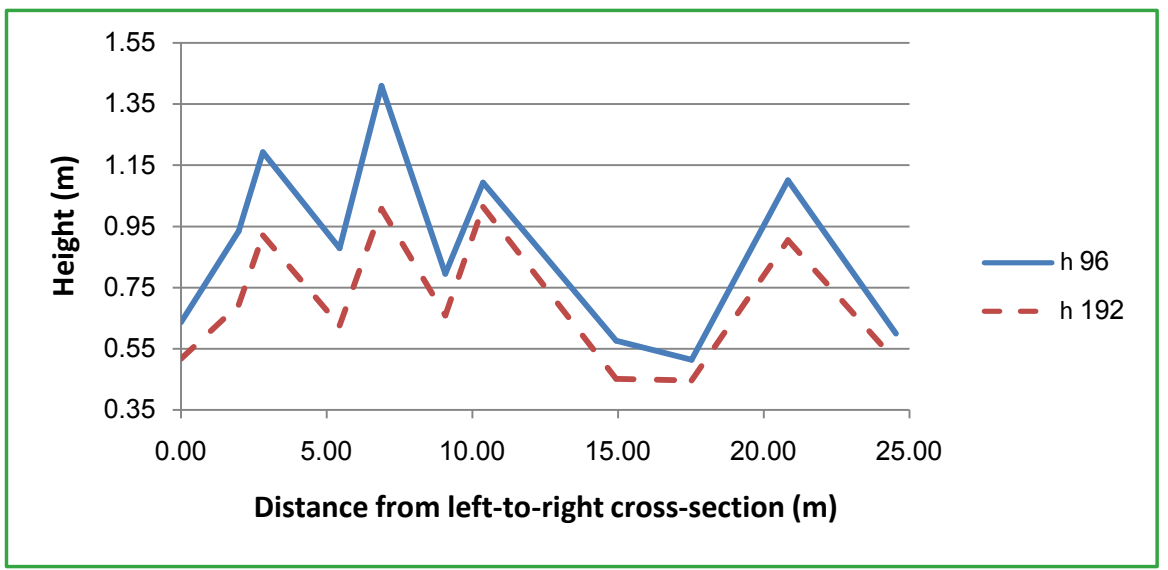

Figure 4. Longitudinal profiles of speed in this research.

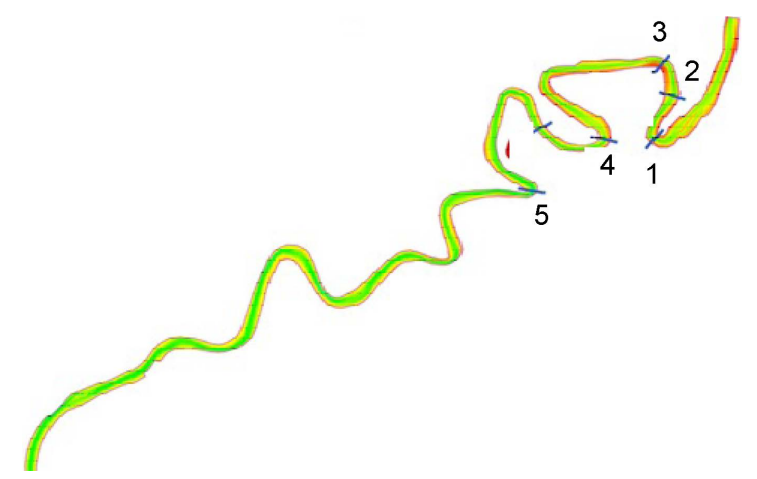

Figure 5. The cross sections selected for getting output.

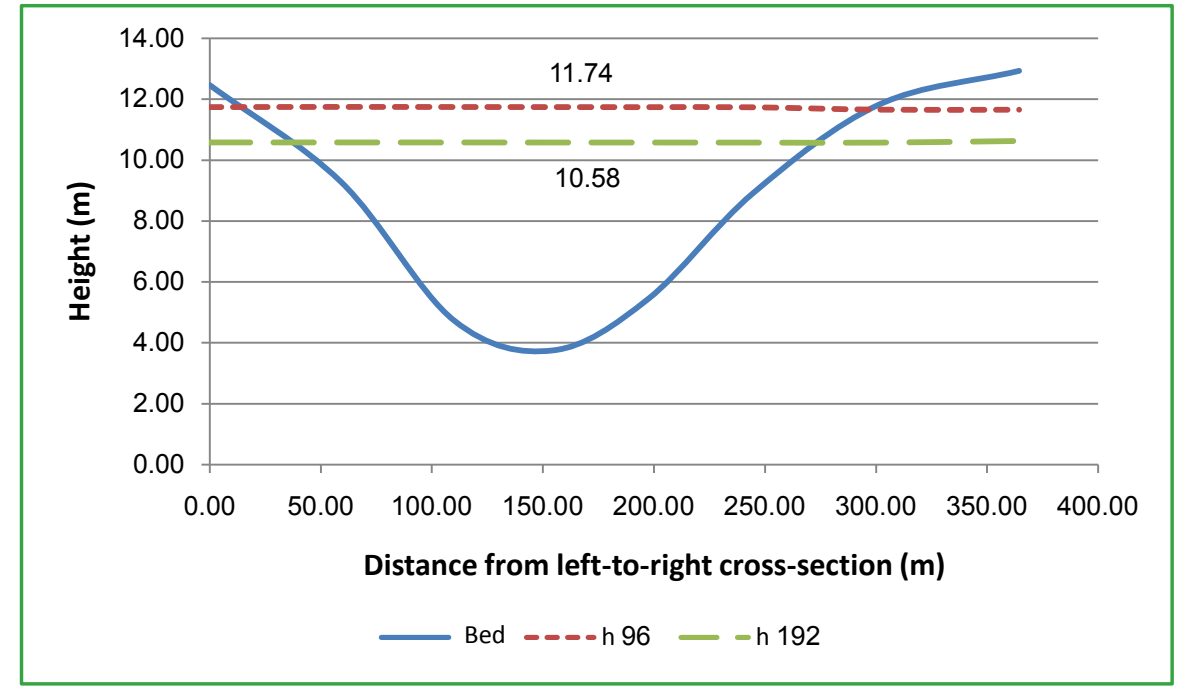

Figure 6. Bed elevation and water levels in cross-section No. 1. 


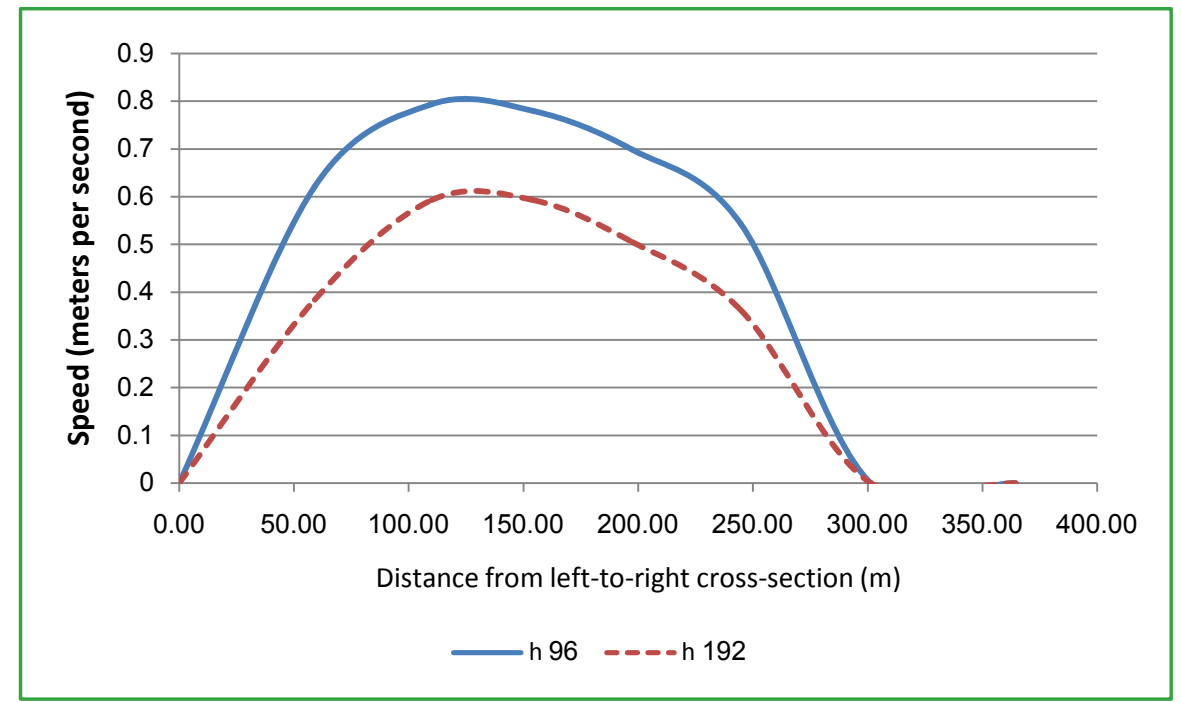

Figure 7. Velocity profile in cross-section No. 1.

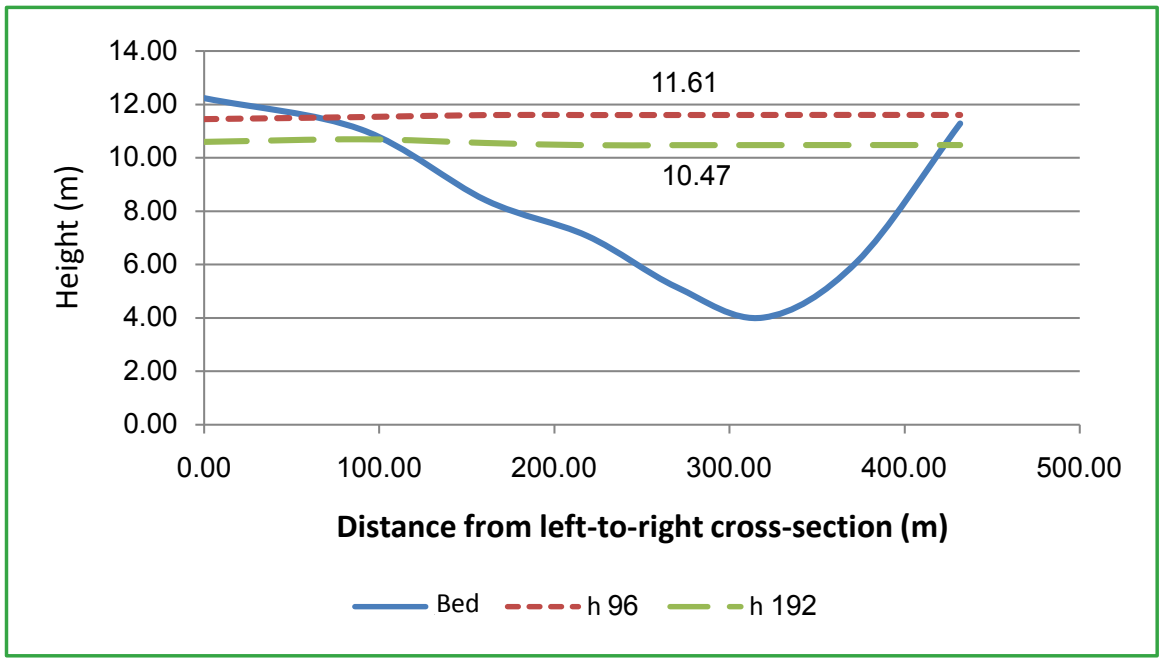

Figure 8. Bed elevation and water levels in cross-section No. 2.

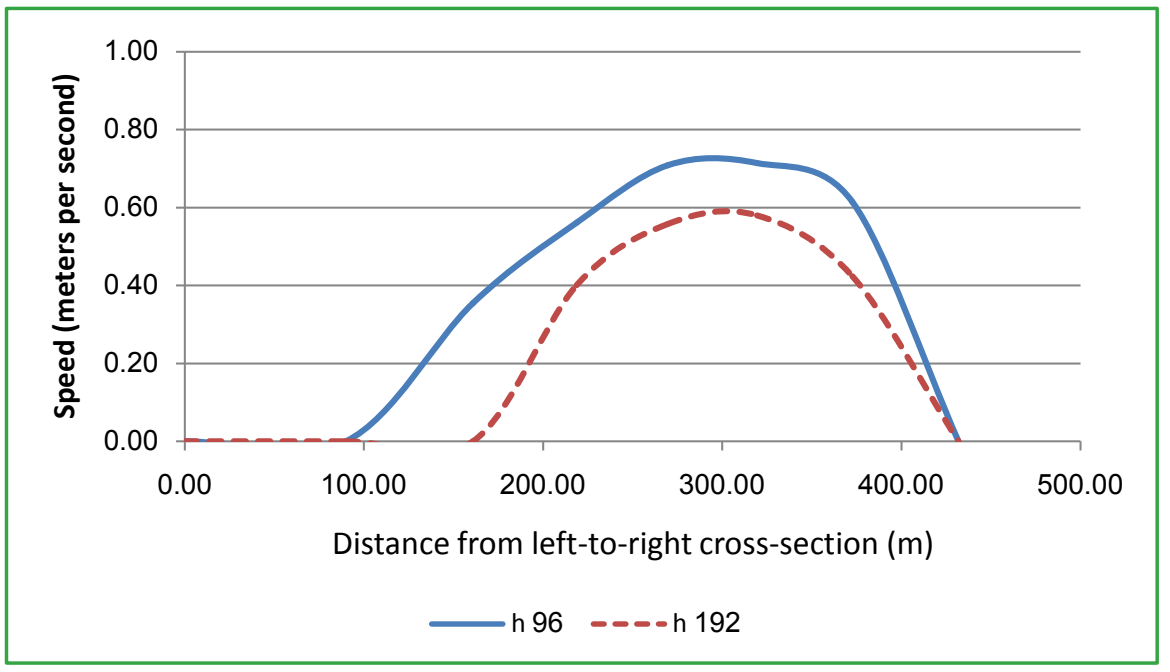

Figure 9. Velocity profile in cross-section No. 2. 


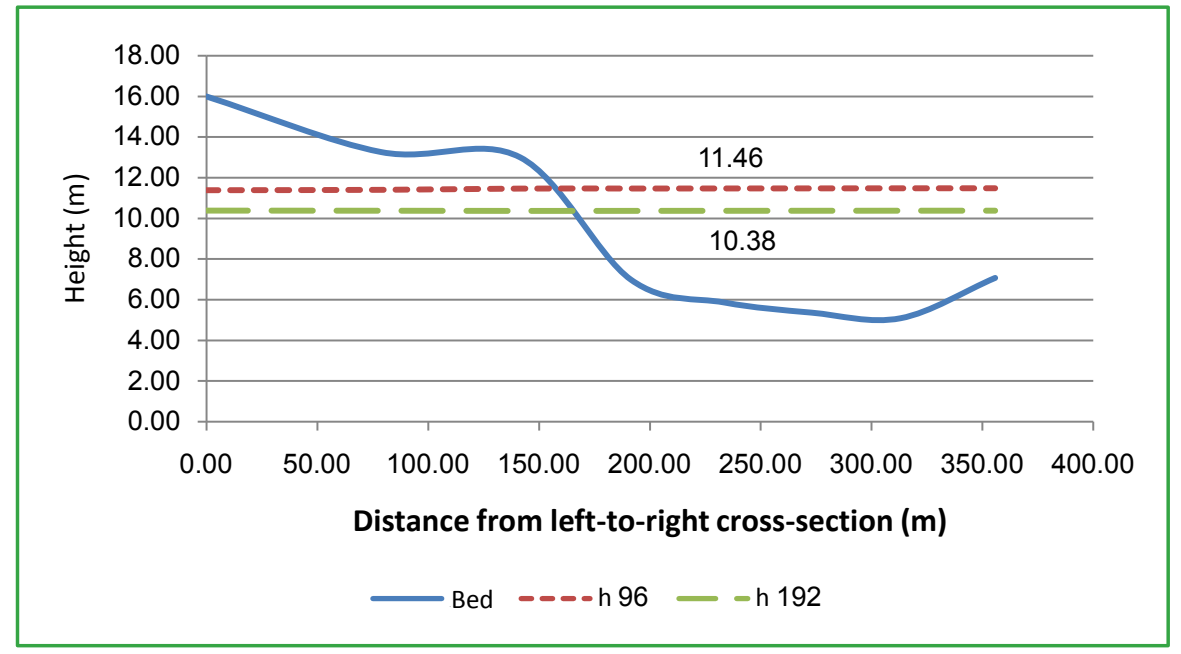

Figure 10. Bed elevation and water levels in cross-section No. 3.

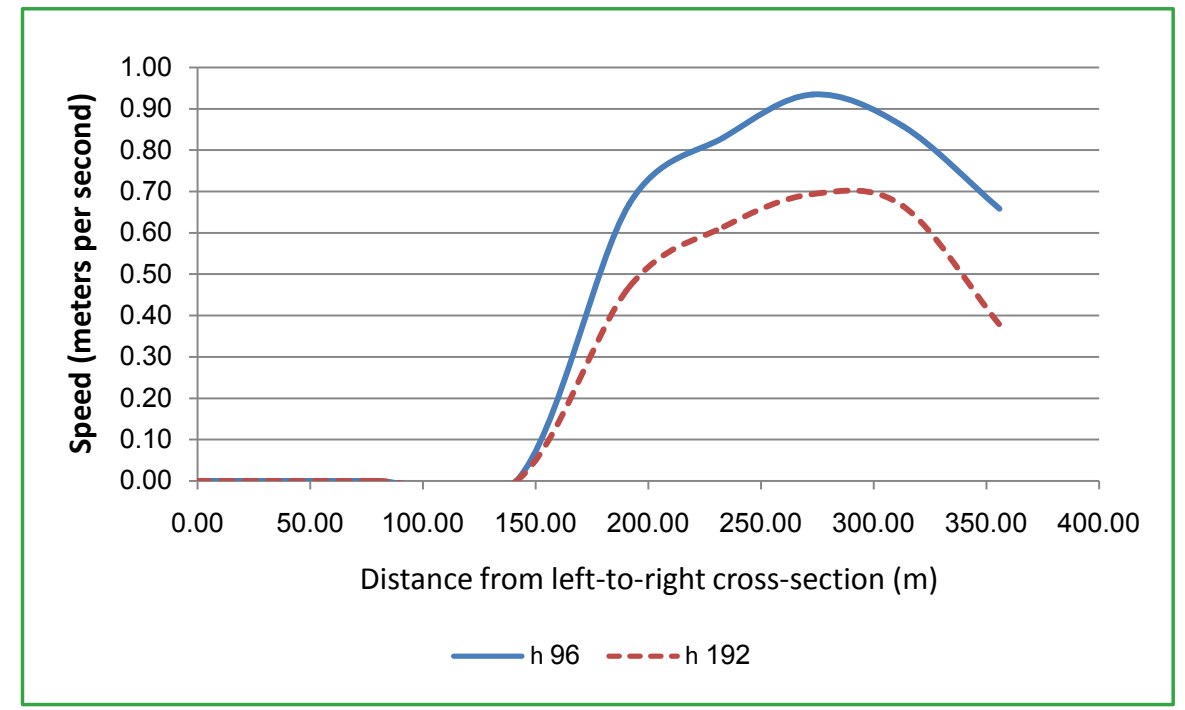

Figure 11. Velocity profile in cross-section No. 3.

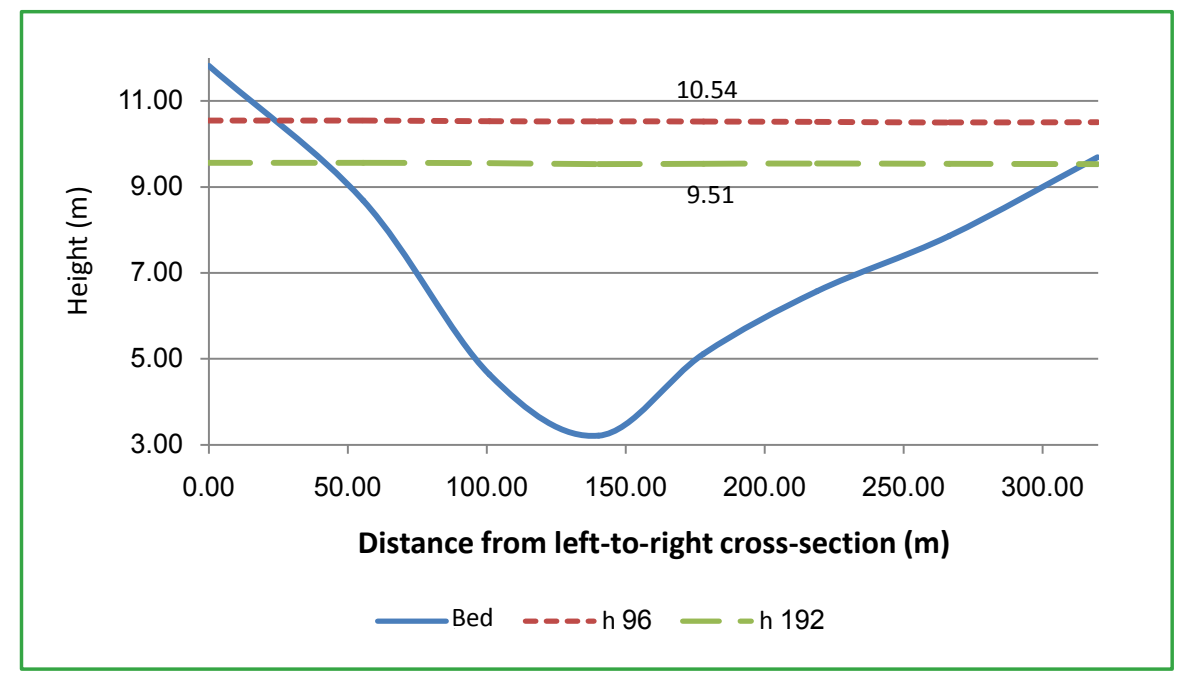

Figure 12. Bed elevation and water levels in cross-section No. 4. 


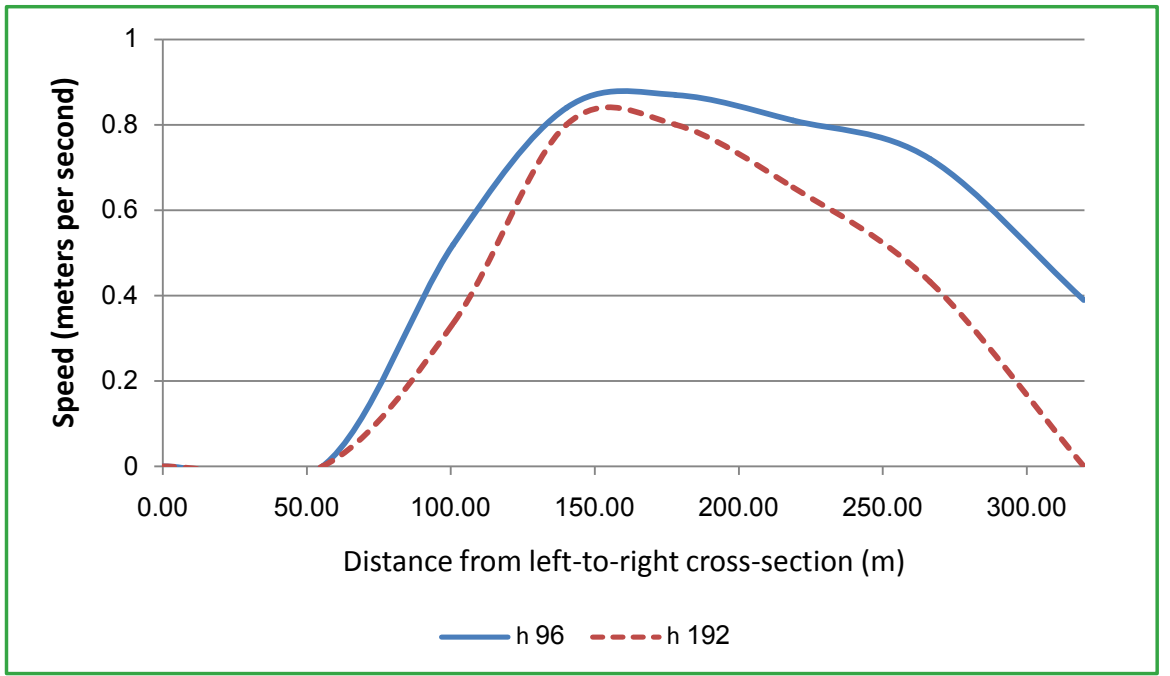

Figure 13. Velocity profile in cross-section No. 4.

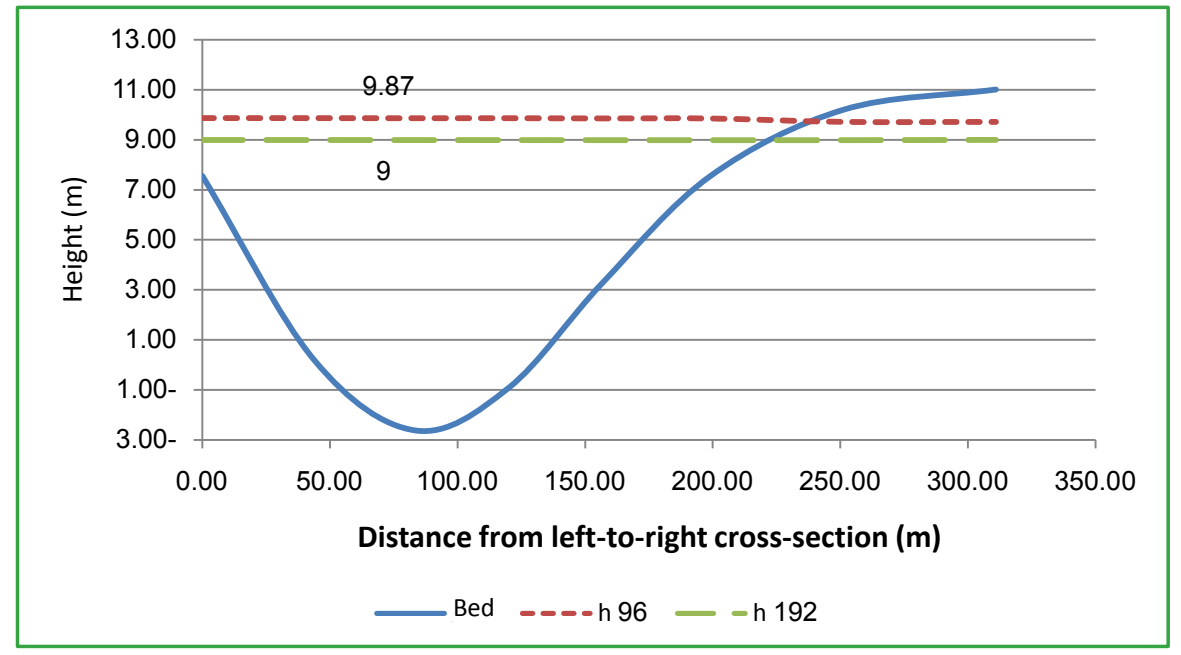

Figure 14. Bed elevation and water levels in cross-section No. 5.

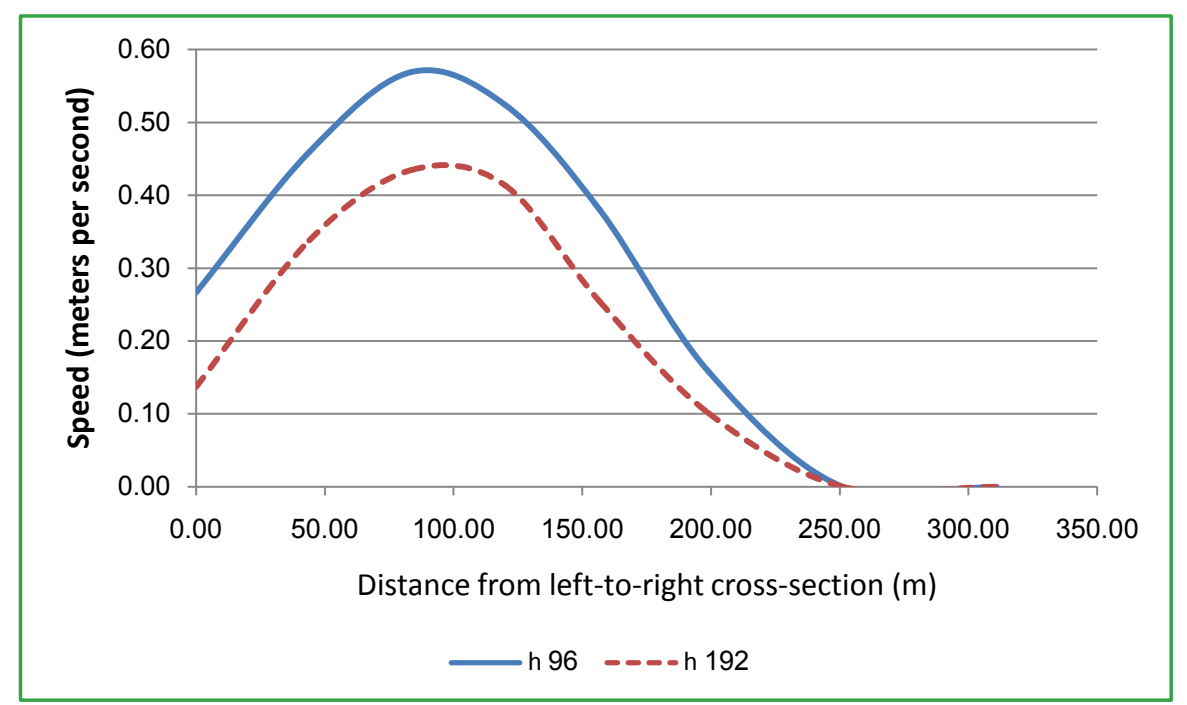

Figure 15. Velocity profile in cross-section No. 5. 
the left of the diagram corresponds to the left side of cross-section (observer's seeing angle is along the flow direction). At this point, difference between the level of water in 96 hours (fourth day) in the middle of the inflow hydrograph compared to the level of water in time 192 hours (eighth day) at the end of the hydrograph is nearly 1 meter. In Figure 13 that shows the changes in the velocity profile in cross-section 4, two important things can be understood. One point is that the culmination point of the curve is close to left; that is outer arch that is logical considering the status of flow. Another point is that the drop in speed after 192 hours on the eighth day is more in the sides, which is due to the reduced level of water and thus reduced flow depth and cross-sectional area. On the other hand, this reduction, on the right (inner arch) of the cross-section is more. Due to the slope below the low wall on this side of the river shallow stream more because due to low inclination of the river wall, water flow reduction is more and as a result we see more speed reduction. Here, too, the results of calculations of the model are logical and is evaluated with acceptable accuracy. The point is that at this point, up to a distance of about 50 meters from the source, because of the drought, the flow rate is zero. In general, the calculation process of the cross sections studied showed that in bents, the model has calculated the flow parameters well. Moreover, maximum speed values in bends are towards the outer arc that shows erodibility of the outer wall in the bends. Distribution and change of pattern of flow parameters by two-dimensional flow model CCHE2D is reasonable and evaluated to have acceptable accuracy and the model can be used for other processes such as sediment transport, river track changes and movements of meandering, erosion and flow analysis at the toe of structure and so on.

\section{References}

[1] Maghrebi, M. (2011) MIKE21 FM CCHE2D Compare Models and Simulate the Flow Pattern in River Bend (Case Study: Karun River). Proceedings of the 1 st International Conference and the National Conference of Dams and Hydroelectric Power Plants, Tehran.

[2] Hayati, A., Niknam, A., Khosravi, Gh. and Kazemi, M. (2014) Examining the Effect of the Changes in River Flood Discharges by Using CCHE2D (Case Study: Kor River, Located between the Bridge and the Dam Abbas Abad). Proceedings of the 1 st Regional Conference of the Sea, the Development of Water Resources and Coastal Areas of the Persian Gulf, Bandar Abbas.

[3] Bahadori, S. and Behdarvandi Askar, M. (2016) Investigating the Effect of Relative Depth and Relative Roughness on Momentum Transfer in Symmetric Rectangular Compound Channels with Varius Relative Width. International Journal of Hydraulic Engineering, 5, 1-8.

[4] Bahadori, S. and Behdarvandi Askar, M. (2016) Investigating the Effect of Relative Width on Momentum Transfer between Main Channel and Floodplain in Rough Rectangular Compound Channel Sunder Various Relative Depth Condition. Open Journal of Geology, 6, 225-231. https://doi.org/10.4236/ojg.2016.64020

[5] Deilami-Tarifi, M., et al. (2016) Modeling of the Changes in Flow Velocity on Seawalls under Different Conditions Using FLOW-3D Software. Open Journal of Marine Science, 6, 317-322. https://doi.org/10.4236/ojms.2016.62026

[6] Ebrahimi, A., et al. (2015) Investigation of Various Random Wave Run-Up 
Amounts under the Influence of Different Slopes and Roughnesses. Environment Conservation Journal, 16, 301-308.

[7] Ghatarband, M. and Behdarvandi Askar, M. (2016) Investigation of the Effect of the Circular Stands Diameters of Marine Structures and the Distances between Them on Wave Run-Up and Force. Marine Science, 6, 11-15.

[8] Rashidinasab, M. and Behdarvandi Askar, M. (2017) Modeling the Pressure Distribution and the Changes of Water Level around the Offshore Platforms Exposed to Waves, Using the Numerical Model of Flow 3D. Computational Water, Energy, and Environmental Engineering, 6, 97-106. https://doi.org/10.4236/cweee.2017.61008

[9] Bahadori, S. and Behdarvandi Askar, M. (2016) Investigating the Effect of Latitudinal Slope of Floodplain and Relative Roughness on Apparent Shear Stress in Symmetric Compound Rectangular Channels with Various Relative Width. Journal of Engineering and Applied Sciences, 11, 57-62.

[10] Mifoor, I., et al. (2016) On the Investigation of Basic Parameters of Designing Protective Layer of the Offshore Breakwaters at Iran's Kharg Island. International Journal of Recent Scientific Research, 7, 9821-9823.

[11] Bahadori, S. and Behdarvandi Askar, M. (2015) Investigating the Simultaneous Effect of Relative Width and Relative Roughness on Apparent Shear Stress in Symmetric Compound Rectangular Channels. Journal of Current Research in Science, 1, 654-660.

[12] Behdarvandi Askar, M. and Moghadam, M.F. (2013) Momentum Attraction by Flood Plains in Compound Channel. Journal of Engineering and Technology, 2, 715.

[13] Deilami-Tarifi, M., et al. (2015) Effect of Slope, Size, and Arrangement of Roughness of Sea Wall on Overtopping of Random Waves. International Journal of Biology, Pharmacy and Applied Sciences, 4, 1026-1034.

[14] Fathi-Moghadam, M., et al. (2010) Effect of Tall Vegetation on Sediment Transport by Channel Flows. Journal of Hydraulic Research, 48, 831-832. https://doi.org/10.1080/00221686.2010.534265

[15] Behdarvandi Askar, M. and Fathi Moghadam, M. (2014) Studying Momentum Transfer between the Sub-Sections of a Symmetric Compound Rectangular Section Using Force Measurement Method. Indian Journal of Scientific Research, 4, 248257.

\section{Submit or recommend next manuscript to SCIRP and we will provide best service for you:}

Accepting pre-submission inquiries through Email, Facebook, LinkedIn, Twitter, etc. A wide selection of journals (inclusive of 9 subjects, more than 200 journals)

Providing 24-hour high-quality service

User-friendly online submission system

Fair and swift peer-review system

Efficient typesetting and proofreading procedure

Display of the result of downloads and visits, as well as the number of cited articles

Maximum dissemination of your research work

Submit your manuscript at: http://papersubmission.scirp.org/

Or contact ojms@scirp.org 